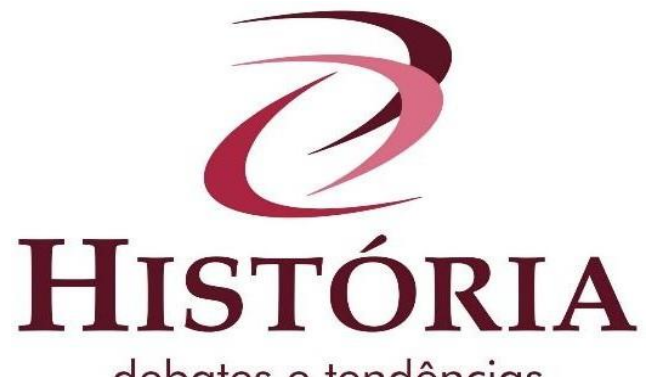

\title{
Quilombos em Minas Gerais: a titulação em terras de interesse transnacional
}

\section{Quilombos in Minas Gerais: land ownership of transnational interest}

\section{Quilombos en Minas Gerais: el título de tierras de interés transnacional}

\author{
Claudelir Correa Clemente ${ }^{\mathrm{i}}$
}

Resumo: Pretende-se analisar quais os pilares culturais e as estratégias que fortalecem vínculos sociais comunitários e dotam de poder de argumentação e negociação a Associação dos Remanescentes dos Quilombos das Famílias Teodoro de Oliveira e Ventura (ARQTOV). Essa associação luta pelo título de suas terras e está exposta à crescente especulação mercantil de seus territórios situados na mesorregião do Triângulo Mineiro e Alto Paranaíba. A mesorregião em questão é rica em terras raras e portadora de fontes de metais como o nióbio, sendo alvo da cobiça agrária e de processos de estrangeirização de terras que atraem mineradoras transnacionais. A perspectiva analítica é antropológica e assentar-se-á na atual concepção de quilombo, na etnografia das experiências sociais locais, em dados jornalísticos e nas análises sobre processos de estrangeirização da terra.

Palavras-chave: quilombo, transnacionais, estrangeirização das terras, Minas Gerais.

\begin{abstract}
We intend to analyze which cultural pillars and which strategies strengthen community social bonds and empower the Association of the Teodoro de Oliveira and Ventura Families Remnants (ARQTOV) for arguing and negotiating. The association fights for the ownership of their land and is currently exposed to an increasing mercantile speculation of its territories in the mesoregion of Mineiro Triangle and High Paranaíba. That mesoregion is rich in rare earths and carries sources of metals such as niobium, being the target of agrarian covet and land alienation processes that attract transnational mining companies. The analytical perspective is anthropological and it will be based on the current conception of quilombo (Brazilian community of slave descendants), the ethnography of local social experiences, newspaper data and the analysis of land alienation processes.
\end{abstract}

Keywords: quilombo, transnational companies, land foreignization, Minas Gerais

Resumen: Nuestro objetivo es analizar qué pilares y estrategias culturales fortalecen los lazos sociales de la comunidad y dotan de poder de discutir y negociar a la Asociación de los Remanentes de los Quilombos de las Familias Teodoro de Oliveira y Ventura (ARQTOV). La Asociación lucha por el título de sus tierras y queda expuesta a la creciente especulación comercial de sus territorios, ubicados en la mesorregión Triángulo Minero y Alto Paranaíba. La mesorregión en cuestión es rica en tierras raras y contiene fuentes de 
metales como el niobio, siendo el objetivo de la codicia agraria y de los procesos de alienación de tierras que atraen a las empresas mineras transnacionales. La perspectiva analítica es antropológica y se basará en la concepción actual de quilombo (comunidades de descendientes de los esclavos brasileños), la etnografía de las experiencias sociales locales y el análisis de los procesos de alienación de tierras.

Palabras clave: quilombo, extranjerización de las tierras, Minas Gerais

\section{Introdução}

Persistir, na atualidade, nos estudos das comunidades rurais negras, em especial das remanescentes comunidades de quilombo que lutam pela titulação de seus territórios, justifica-se pelo fato de que as experiências quilombolas portam dimensões culturais, jurídicas e políticas que permitem compreender facetas das lutas sociais brasileiras. Elas remetem ao passado escravagista e revelam um presente marcado por enfrentamentos contra a discriminação e o racismo. Vamos tomá-las como condutoras deste artigo, com o objetivo de proporcionar ao leitor uma visão mais ampla sobre a condição dos territórios quilombolas em Minas Gerais, um estado sem quilombos titulados pelo Instituto Nacional de Colonização e Reforma Agrária (INCRA).

O artigo tem como base um estudo antropológico da Associação dos Remanescentes dos Quilombos das Famílias Teodoro de Oliveira e Ventura (ARQTOV), cujas famílias estão distribuídas nas cidades da mesorregião do Triangulo Mineiro e Alto Paranaíba, em específico em, Cruzeiro da Fortaleza, Patos de Minas, Patrocínio e Serra do Salitre. O estudo foi realizado entre os anos de 2017 a 2019. A região onde estão localizadas as famílias da ARQTOV é um local de forte especulação mineraria e onde estão presentes grandes corporações transnacionais. Isso requereu a articulação de diferentes fontes de informação e metodologias de pesquisa, para o artigo oferecer aos leitores, uma melhor compreensão de como operam as empresas transnacionais na região e a relação entre essas instituições e a população quilombola.

Portanto, a presente analise, além de dialogar com a teoria antropológica sobre quilombos, de apresentar aspectos etnográficos das experiencias sociais das famílias da ARQTOV, incorpora alguns dados veiculados na grande imprensa, em especial reportagens focadas nas empresas do setor de mineração e dados veiculados na mídia comunitária local, em que há matérias feitas por jornalistas locais de origem quilombola e que realçam o empenho da ARQTOV na luta pela titulação de suas terras e preservação de sua cultura. 
A partir dos dados e análises sobre a realidade atual das remanescentes comunidades de quilombos, buscamos compreender os pilares culturais e as estratégias que fortalecem vínculos sociais comunitários e dotam de poder de argumentação e negociação a Associação dos Remanescentes dos Quilombos das Famílias Teodoro de Oliveira e Ventura (ARQTOV) que luta pela titulação de suas terras e está exposta a crescente especulação mercantil de seus territórios situados na Mesorregião do Triangulo Mineiro e Alto Paranaíba.

Nesse sentido, este artigo se propõe a discutir alguns assuntos e temas. Numa primeira parte, o texto evidencia aspectos da luta das comunidades rurais negras a partir da promulgação da Constituição de 1988 e discute o impacto dessa luta sobre a redefinição do conceito de quilombo.

$\mathrm{O}$ artigo segue seu desenvolvimento conduzido pelas experiências sociais das comunidades rurais negras da Mesorregião do Triangulo Mineiro e Alto Paranaíba, autointituladas quilombolas, e busca expor as dificuldades que os afrodescendentes enfrentam para afirmar sua memória ancestral, sua cultura de matriz africana e seu território - espaço social, histórico, econômico e simbólico - numa região dominada pelo capitalismo transnacional que cobiça os bens de suas terras.

Nessa mesorregião, o mercado de terras raras atrai grandes empresas transnacionais de mineração e de fertilizantes que impactam, na maioria das vezes, desastrosamente na vida social local.

\section{A Noção de quilombo após a constituição de 1988}

Os anos de 1980 foram significativos e prósperos para as comunidades rurais negras. Tempo de enaltecimento de suas lutas sociais seguido de conquistas, como a aprovação do artigo 68 do Ato das Disposições Constitucionais Transitórias (ADCT) da Constituição Brasileira de 1988, que estabeleceu que "aos remanescentes das comunidades de quilombos que estejam ocupando suas terras é reconhecida a propriedade definitiva, devendo o Estado emitir-lhes os títulos respectivos". (BRASIL, CONSTITUIÇÃO de 1988)

Para a antropologia, a promulgação da Constituição significou uma maior aproximação dos estudos quilombolas e dos debates sobre o reconhecimento dos direitos territoriais dos remanescentes de quilombo, até então um campo de pesquisa quase que exclusivo da historiografia.

De acordo com Eliane Cantarino O`Dwyer (2002): 
Pode parecer paradoxal que os antropólogos, que marcaram suas distâncias e rupturas com a historiografia (ao definir seu campo de estudos por um corte sincrônico no "presente etnográfico"), tenham sido colocados no epicentro dos debates sobre a conceituação de quilombo e sobre a identificação daqueles qualificados como remanescentes de quilombos, para fins de aplicação do preceito constitucional. Acontece, porém, que o texto constitucional não evoca apenas uma "identidade histórica" que pode ser assumida e acionada na forma da lei. Segundo o texto, é preciso, sobretudo, que esses sujeitos históricos presumíveis existam no presente e tenham como condição básica o fato de ocupar uma terra que, por direito, deverá ser em seu nome titulada (como reza o artigo $68^{\circ}$ do ADCT) (O' DWEYER 2002, p.14).

Prontamente, o Comitê Quilombos, da Associação Brasileira de Antropologia (ABA), em meados dos anos 1990, mobilizou-se para atualizar o conceito de quilombo, realçando, através da etnografia de pesquisadores que atuavam em comunidades rurais negras, a diversidade das experiências quilombolas. As discussões sobre grupos étnicos e etnicidade, inspiradas por autores como Frederik Barth (1969) e Manuela Carneiro da Cunha (1979), levariam também a antropologia brasileira a localizar no presente etnográfico os traços que distinguem os grupos, pois, conforme O’Dwyer (2002),

O fato de o pressuposto legal estar referido a um conjunto possível de indivíduos ou atores sociais organizados em conformidade com sua situação atual permite conceituá-los, sob uma perspectiva antropológica mais recente, como grupos étnicos, que existem ou persistem ao longo da história como um 'tipo organizacional' (sic) segundo processos de exclusão e inclusão que permitem definir os limites entre os considerados de dentro e de fora. (O’DWYER, 2002 p.14)

Operar antropologicamente com a noção de grupo étnico significou tornar relevantes as diferenças culturais destacadas pelos próprios quilombolas no seu processo de autoidentificação. De acordo com o antropólogo Carlos Eduardo Marques (2009),

Falar em etnia como existência coletiva, como uma área de fronteiras ou, no sentido adotado por Weber (2004), em que etnicidade é um instrumento político (de organização sociopolítica) -, é reforçar a importância da etnografia e do estar lá, visto que não se trata mais de dizer o que o outro é, de forma arbitrária e com base em critérios pretensamente objetivos, e sim de permitir que a subjetividade, o contexto e a mobilização dos sujeitos de direitos, formadores de uma identidade coletiva, se expressem. Não se está diante de um a priori histórico, jurídico, arqueológico ou sociológico, e sim de uma afirmação identitária pela contraposição, através da autoatribuição (MARQUES, 2009 p. 353). 
A promulgação da constituição e a necessidade de regulamentação do Artigo 68 provocaram discussões que promoveram a redefinição da noção de quilombo com vistas a atender a atual pluralidade quilombola composta por grupos que de acordo do com Schmitt, 2002 constituem-se,

a partir de uma grande diversidade de processos, que incluem as fugas com ocupação de terras livres geralmente isoladas, mas também as heranças, as doações, recebimento de terras como pagamento de serviços prestados ao Estado, a simples permanência nas terras que ocupavam e cultivavam no interior das grandes propriedades, bem como a compra de terras, tanto durante a vigência do sistema escravocrata quanto após a sua extinção (SCHMITT, 2002 p.3).

Referendados por essa noção mais ampliada e inclusiva de quilombo, muitas comunidades negras cuja experiencia social condizia com a condição quilombola, passaram a organizar-se para pleitear a titulação de suas terras.

O primeiro quilombo a ser reconhecido conforme o ADCT 68, foi o da comunidade Boa Vista no Alto Trombetas, no município de Oriximiná no estado do Para, em 1995.

Outro fato importante para o refinamento da noção de quilombo ocorreu em 2003, quando o então presidente Luís Inácio Lula da Silva promulga o decreto presidencial 4.887 de 2003 ampliando as possibilidades de titulação de territórios quilombolas.

A obtenção da titulação das terras segue um rigoroso processo que inicia com organização das famílias quilombolas e ou comunidade em uma associação que solicitará a certificação de suas terras junto a Fundação Cultural Palmares, nessa etapa as famílias e comunidade quilombola, apenas tem a certificação, mas não a posse da terra.

Geralmente a sociedade civil mais ampla, por desinformação acredita que a etapa da certificação já caracteriza a posse da terra, no entanto, isso é apenas o início da árdua luta pela conquista do título de posse coletiva por definitivo.

Após a certificação há um longo caminho a titulação que passa pela produção do relatório técnico de identificação e delimitação (RTID), na maioria das vezes feito pela associação quilombola em conjunto com uma assessoria de uma equipe multidisciplinar composta por antropólogos, historiadores, geógrafos, arqueólogos, advogados. Todo o processo só finaliza com a outorga do título pelo INCRA.

A seguir a figura 1 nos apresenta o número de terras quilombolas tituladas e parcialmente tituladas e o número pedidos de terras quilombolas em processo no INCRA. 


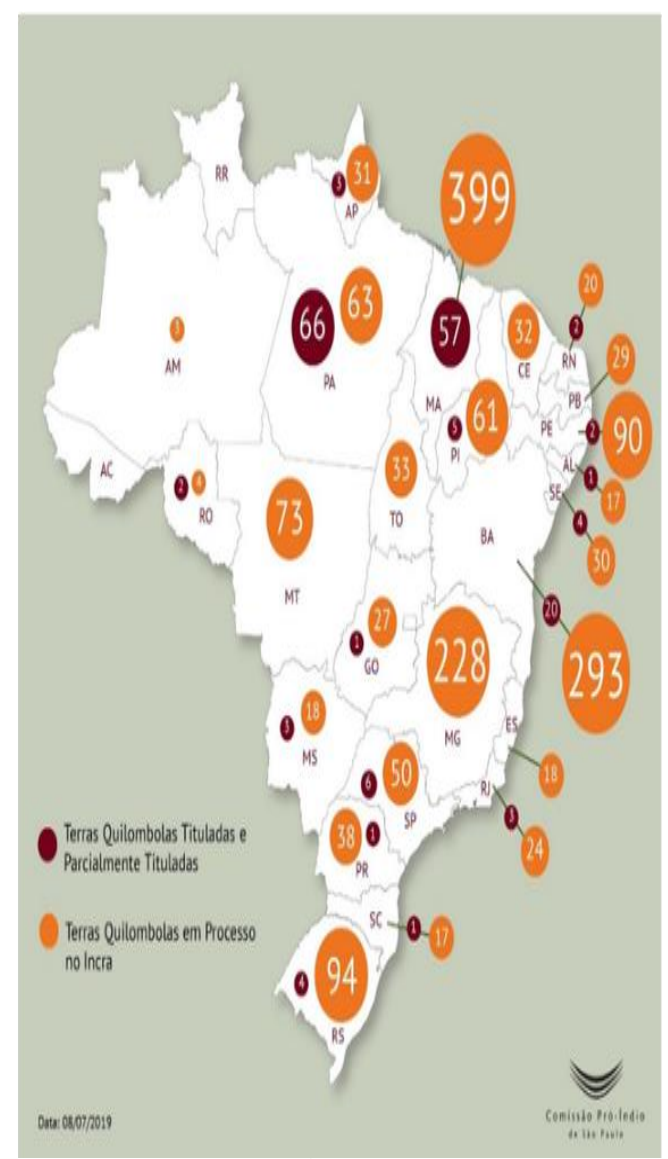

Fonte: Comissão Pró-Índio de São Paulo.

O que intriga na figura 1 é constatar que Minas Gerais, um dos locais que nos tempos coloniais recebeu um contingente significativo de africanos escravizados que forçadamente trabalhavam nas minas de ouro, cujo auge da exploração foi entre os séculos XVII e XVIII, figura como um dos estados que até 2019, não possuía quilombos titulados pelo INCRA.

Os quilombolas mineiros da Associação dos Remanescentes dos Quilombos das Famílias Teodoro de Oliveira e Ventura (ARQTOV), cujas famílias estão distribuídas nas cidades da mesorregião do Triangulo Mineiro e Alto Paranaíba é um dos casos que vive o desafio em titular suas terras pela INCRA. Para eles, a presença na região um forte processo de estrangeirização da terra dificulta ainda mais o processo de titulação.

\section{Cultura negra quilombola no Triangulo Mineiro e Alto Paranaíba}

O que conhecemos hoje por Mesorregião do Triângulo Mineiro e Alto Paranaíba é, sobretudo, um espaço que reúne antigas comunidades vinculadas a conhecimentos 
tradicionais, como produção de queijo Canastra, criação de aves e produção de café. Muitos dos seus habitantes são quilombolas.

Nessa mesorregião,

\begin{abstract}
a cultura negra adquiriu historicamente papel central nas inúmeras práticas culturais populares verificadas nos diferentes municípios, vilas e vilarejos locais [...] Os primeiros registros históricos da cultura afro-brasileira no Triângulo Mineiro associam-se à descoberta de jazidas de ouro e diamantes no interior de Goiás e Mato Grosso, ainda no século XVIII. A mineração que por essa época se deslocava para o Centro-Oeste foi a principal responsável pela formação dos primeiros arraiais (SILVA 2013 p.13-14).
\end{abstract}

Um dos quilombos mais combativos da história mineira localizou-se nessas redondezas. Trata-se do então Quilombo do Ambrósio, que, devido aos intensos combates que enfrentou no século XVIII, deslocou-se por muitas cidades mineiras que na atualidade estão distribuídas tanto na Mesorregião do Triângulo Mineiro e Alto Paranaíba como no oeste de Minas. As definições das áreas ocupadas pelo quilombo histórico e de seus trajetos e itinerários, durante seus deslocamentos provocados pelas batalhas que travou com a administração colonial, ainda provocam nos dias de hoje discussões. Uma nova corrente de estudos histográficos tem se dedicado a reconstruir o passado do Quilombo do Ambrósio. As análises de Jeremias Brasileiro (2017) apontam dados importantes que discutem com mais propriedade o assunto.

Para a análise que aqui desenvolvemos cabe destacar que são etnograficamente perceptíveis nos dias de hoje redes de parentesco e laços de afinidade que ligam as atuais comunidades negras da região do Alto Paranaíba ao histórico Quilombo do Ambrósio. Durante inserções etnográficas realizadas desde 2017, em que participei de rodas de conversa com populações negras da região, constatou-se que a memória do Quilombo do Ambrósio se reaviva, sendo comum ouvir assuntos que versam sobre o parentesco das atuais famílias com membros desse quilombo.

Em especial, Associação dos Remanescentes dos Quilombos das Famílias Teodoro de Oliveira e Ventura (ARQTOV) tem mostrado profundo empenho em demonstrar seu parentesco com o histórico Quilombo Ambrósio, além de possuírem uma vasta documentação sobre terras que lhes foram doadas por fazendeiros no início do século XX.

Com base nesses documentos a ARQTOV consegue sua certificação pelo Instituto Nacional de Colonização e Reforma Agrária (Incra) em 2008 e após 9 (nove) anos, com a análise do Relatório Técnico de Identificação e Delimitação (RTID), consegue a publicação 
da portaria no Diário Oficial da União de 13/11/2017 que lhes dá a possibilidade de continuar o processo pela titulação das terras.

Os membros dessas famílias estão distribuídos no Triângulo Mineiro e Alto Paranaíba e também em alguns outros estados brasileiros. No entanto, sua maior concentração se dá nos municípios Cruzeiro da Fortaleza, Patos de Minas, Patrocínio e Serra do Salitre.

Conforme informações do Incra, acessadas através do CEDEFES ${ }^{\mathrm{ii}}$ as famílias Teodoro de Oliveira e Ventura são descendentes

de três irmãs: Luiza, Joaquina e Rita Theodora de Oliveira que herdaram, por testamento, os bens de José da Silva Botelho, escravizador da mãe dessas senhoras. Entre 1920 e 1960, ocorreu um processo de expropriação do território que levou os ramos de descendentes das três irmãs a uma diáspora para outras cidades como Brasília, Belo Horizonte e São Paulo (CEDEFES,2017).

Ainda de acordo com o CEDEFES,

O RTID é composto pelo relatório antropológico, levantamento fundiário, planta e memorial descritivo, cadastramento das famílias e levantamento de eventuais sobreposições dos imóveis que constituem a área pleiteada, que no caso da Teodoro de Oliveira soma 3.863 hectares (CEDEFES,2017).

As discussões geradas em torno do RTID da ARQTOV nos permitiram adentrar com maior profundidade nos assuntos ligados à exploração de minérios e terras raras na região do Alto Paranaíba.

Com a publicação do RTID, as famílias quilombolas tiveram um prazo de 90 dias para contestar o relatório, e isso foi feito. Para tanto, retornaram às áreas territoriais delimitadas pelo relatório e se depararam com uma situação de destruição de alguns bens culturais e redução territorial. Tal constatação foi descrita na reportagem de 28/12/2017, feita e veiculada pelo canal de notícias $A$ voz do povo, mídia organizada por um pool de agentes comunitários de comunicação vinculados às cidades de Cruzeiro da Fortaleza, Patrocínio e Serra do Salitre.

Assim, se lê no site de notícias:

O sr. José Antônio Ventura, presidente da Federação Nacional dos Quilombolas e presidente da Associação das Famílias Quilombolas Teodoro de Oliveira e Ventura, compareceu a Procuradoria da República 
de Patos de Minas, na data de 27/12/17, afirmando que vários bens que estão dentro da área reivindicada pelos quilombolas e demarcada pelo INCRA, no RTID, estão sendo destruídos, destacou: parte da Fazenda da Serrinha, onde haviam ruínas de construções realizadas pelos escravos, os muros construídos pelos escravos (sítios arqueológicos tombados pelo IPHAN). Os muros de pedras, muros divisórios construídos pelos escravos no limite da chácara Moitinha, a casa de trezentos anos, todas localizadas no município de Serra do Salitre/MG. Ainda afirma que foram realizados loteamentos de forma massiva na antiga sede da Fazenda Serrinha. Ainda afirma também o representante que todos os bens relacionados acima estão dentro da área delimitada no RTID, realizado pelo INCRA e objeto da Ação Civil proposta pelo Ministério Público Federal nos autos $\mathrm{n}^{\circ}$ 0003545-82.2016.4.01.3806 (DIVINO, 2018).

As contestações da ARQTOV ao RTDI revelam outros fatores desencadeados durante a tramitação do relatório no Incra. As conquistas constituídas ao longo do processo de certificação e realização do RTID estavam sofrendo um processo de apagamento, expresso nos loteamentos massivos e na destruição de bens históricos e arqueológicos ligados às experiências sociais de escravização de membros antepassados da rede familiar dos Teodoro Oliveira e Ventura.

O processo de invisibilização da história social negra é intenso e constante, em especial nesse espaço da ARQTOV, que outrora foi constituído de fazendas escravagistas, e atualmente é um dos espaços mais cobiçados por mineradoras e empresas de fertilizantes transnacionais.

\section{Mineradoras Transnacionais eo processo de estrangeirização de terras em Minas Gerais}

Sem dúvida há uma relação entre as contestações levantadas pela ARQTOV no (RTID) e a atração desenfreada de empresas transnacionais pelas cidades da região, como Serra do Salitre, Cruzeiro da Fortaleza, Tapira e Araxá. Esse intenso movimento empresarial deve-se à descoberta de terras raras, com minérios e elementos químicos de preços exorbitantes no mercado internacional.

A exploração minerária nessa região mineira é antiga e remonta aos tempos da Colônia. Sabemos que o estado de Minas Gerais mereceu essa denominação devido a suas riquezas minerais. No entanto, não nos interessa neste artigo analisar a atividade minerária ao longo da história brasileira, mas compreender o impacto dessas mineradoras nos dias de hoje e suas relações com populações quilombolas e demais comunidades rurais habitantes da Mesorregião do Triângulo Mineiro e Alto Paranaíba. 
Nesse sentido, iniciamos nosso mergulho no universo da exploração minerária tendo, como ponto de partida uma notícia veiculada pela grande mídia no Portal G1 sobre a cidade de Serra do Salitre. A matéria anuncia a venda de terras para a Mineradora Galvani. De acordo com a reportagem,

\begin{abstract}
O município de Serra do Salitre, no Alto Paranaíba, está prestes a entrar na rota da mineração. A cidade, onde cerca de $80 \%$ da economia gira em torno da agricultura, receberá a Galvani Complexo Mineiro Industrial da Serra do Salitre. As obras de instalação estão $30 \%$ concluídas e foram orçadas em R $\$ 500$ milhões. A empresa, que durante a obra gerou mais de mil empregos, pretende contratar dois mil trabalhadores no período de pico das obras e gerar 700 empregos diretos e outros 500 indiretos. A previsão é de que o negócio entre em operação no segundo semestre de 2017 com a produção de 1,2 milhão de toneladas de fertilizantes fosfatados por ano. A área industrial tem um milhão e quatrocentos metros quadrados. O gerente de projetos da empresa, Gustavo Horbachi, diz que o espaço será dividido em duas partes. "A gente tem uma área de mineração, que vai ser a primeira a partir do segundo semestre do ano que vem. E uma parte de produção de aços, que vai servir para produzir fertilizantes em 2018 (G1 PORTAL DE NOTICIAS, 2017).
\end{abstract}

A instalação de empresas desse porte gera transformações muito rápidas em municípios pequenos. De acordo com a população local, Serra do Salitre era praticamente um vilarejo sem muita infraestrutura. No censo de 2010 do IBGE, estimava-se uma população de 11 mil habitantes. Atualmente o quadro é outro, o número de habitantes tem se ampliado, o que significa também mais loteamentos para atender ao quadro de funcionários da mineradora. Por isso as inquietações da ARQTOV com a ocupação desordenada na área territorial do quilombo.

Como já destacado, a mesorregião chama atenção devido suas terras oferecerem matéria química mineral: alumínio, chumbo, nióbio, terras raras, zinco e outros minerais, como o fosfato.

Essas atividades em torno das terras raras compõem uma das novas formas de apropriação das terras por grupos empresariais estrangeiros.

Estudiosos do fenômeno da estrangeirização da terra ressaltam que

a apropriação estrangeira de terras faz parte da história da humanidade e, na fase mais recente, isto vem acontecendo há pelo menos cem anos (Sassen, 2013). No entanto, como destacam Edelman e León (2013, p. 1697), a '[...] apropriação de terras tende a ocorrer em ciclos, ou em ondas, dependendo da dinâmica regional e global históricas específicas de acumulação de capital', sendo que 'a extensão da aquisição de terras por governos e empresas estrangeiras e investidores nos últimos anos no Sul 
Global marca uma nova fase.' (Sassen, 2013, p. 29). (SAUER e BORRAS, 2016, p.15).

As aquisições de terra estão principalmente concentradas nos países do Sul e, particularmente nos países africanos e latino americanos Sauer e Leite (2012).

Um dos principais indicadores de apropriação das terras brasileiras por proprietários estrangeiros é o Investimento Estrangeiro Direto (IED). De acordo com Wolffenbüttel (2006): "Investimento estrangeiro direto (IED) é todo aporte de dinheiro vindo do exterior que é aplicado na estrutura produtiva doméstica de um país, isto é, na forma de participação acionária em empresas já existentes ou na criação de novas empresas" (Wolffenbüttel, 2006).

Os IEDs no setor primário brasileiro passaram de US\$ 2,4 bilhões em 2000, indo para US\$ 13,1 bilhões de dólares, em 2007; sendo que a alta de $445 \%$ foi puxada pela mineração, que correspondeu a $71 \%$ do total recebido. Sauer e Leite, (2012).

Para compreendermos o movimento dos IEDs no mercado mineratório, destaco, baseada numa série de reportagens do jornal Folha de S. Paulo (OLIVEIRA, 2011, CASTILHO, 2012) e da Revista Exame (LUCCHESI E CUADROS, 2013), que o aumento dos preços internacionais dos bens minerais, especialmente do grupo dos metálicos, tem provocado novos posicionamentos de países e de empresas.

No final do ano de 2013, cerca de $80 \%$ da demanda de terras raras leves e $100 \%$ da demanda de terras raras pesadas foram atendidas pelo mercado chinês. Contudo, a partir de 2010, a China passou a restringir suas vendas.

A redescobertaiii de terras raras na região brasileira do Alto Paranaíba reacendeu a especulação mercantil após a retração chinesa. Com forte presença do metal nióbio, pequenas cidades mineiras transformaram-se em celeiro tecnológico, onde é movimentado um conjunto de atividades de exploração, demandando recursos humanos, máquinas e equipamentos especializados para a extração dos metais raros.

Esse potencial de exploração química e mineral explica a presença da supracitada Galvani e outras de instalação mais antiga, como a Vale e a Companhia Brasileira de Metalurgia e Mineração (CBMM). Essa última é uma grande empresa com porte transnacional, que possui subsidiárias na Suíça, em Singapura, na Holanda e nos EUA, além de distribuidores no Japão, na China, na Índia e na Rússia. 
A empresa CBMM pertence ao grupo brasileiro Moreira Salles e está instalada em Araxá. Recebe IEDs de empresas asiáticas que de alguma forma passaram a possuir uma certa parte da mina de nióbio mineira.

Com base nos estudos sobre estrangeirização da terra, em específico, em torno da noção de land grabbing, pude compreender mais profundamente o fenômeno da apropriação das terras.

Assim,

nos termos de Mehta, Veldwish e Franco (2012, p. 195), "land grabbing" é, em última instância, 'apropriação do controle", ou seja, a "[...] captura do controle de grandes extensões de terra" (Borras, Franco e Ploeg, 2013 p. 17) é '[...] essencialmente relacional e político, envolvendo relações de poder' (Borras et al., 2012, p. 404) (SAUER e BORRAS, 2016 p.13).

A ideia de apropriação do controle de grandes extensões de terra envolvendo relações de poder captam, na perspectiva deste artigo, a atmosfera que envolve as relações na Mesorregião do Triângulo Mineiro e Alto Paranaíba entre proprietários transnacionais de terra e as populações vizinhas dessas propriedades.

Em especial algumas mineradoras apresentam mecanismos de controle que são erigidos através de seu sistema de comunicação, que busca criar uma imagem de comunidade de empresa sustentável e geradora de empregos. Isso é veiculado através de publicações nos seus sites e de atividades presenciais educativas, que difundem sua preocupação em reabilitar, por exemplo, o meio ambiente local.

De acordo com Deshaies (2011), esse tipo de comunicação ganhou força com o relatório Breaking new ground: mining, minerals and sustainable development, produzido num encontro em maio de 2002 na África do Sul; sua elaboração contou com grandes empresas mineradoras do mundo. Em linhas gerais, o objetivo do relatório Breaking new ground foi mostrar que as mineradoras são também sustentáveis, e isso estaria definido em alguns pilares que destacamos, resumidamente, a seguir:

- Contraposição às atividades predatórias da exploração artesanal mineral, tidas como nocivas ao meio ambiente. As empresas mineradoras possuem práticas de exploração mais avançadas, pois usufruem de técnicas modernas que permitem melhores condições de trabalho e maior rendimento;

- Reabilitação das minas promovida pelas mineradoras responsáveis socialmente, gerando melhorias para o meio ambiente pós-atividade mineral; 
- Necessidade de contribuir para programas educacionais que assegurem o desenvolvimento sustentável. Isso significa atuar junto às comunidades locais e ajudar os seus governos e suas lideranças comunitárias na conquista de melhores resultados na sustentabilidade local.

Ao destacar os conteúdos e as configurações do sistema de comunicação das empresas mineradoras transnacionais, pretende-se analisar tais comunicações a partir umas perspectivas antropológicas, pois se verifica que o processo de estrangeirização da terra acontece também no nível da inculcação pelas comunidades da importância dos serviços das mineradoras transnacionais.

Tanto, algumas das práticas de sustentabilidade e de responsabilidade social desenvolvidas pelas empresas atuantes na Mesorregião do Triângulo Mineiro e Alto Paranaíba parecem suscitar nas comunidades locais níveis de receptividade e positividade. Sem dúvida isso é importante e demonstra o reconhecimento das comunidades pelas empresas.

No entanto, é também perceptível uma cautela na interação com mineradoras, por parte das comunidades quilombolas da região. Do ponto de vista dos quilombos é preciso atenção, já que os empreendimentos empresariais são na maioria das vezes vistos como investimentos que geram muitas desordens de vários níveis: territoriais, econômicas, culturais e simbólicas.

São ocupações que se dão sem um planejamento que contemple a visão das comunidades. Há por parte dos quilombolas uma noção de que o mesmo capital que gera empregos, que ergue coisas belas, também as destrói. Nesse sentido, as comunidades também se organizam e buscam formas de fazer valer seus interesses.

\section{Pilares culturais e estratégias de empoderamento quilombola}

A tentativa de invisibilização da cultura quilombola, legado das Famílias Teodoro de Oliveira e Ventura, constatada na ocasião da revisão do seu Relatório Técnico de Identificação e Demarcação (RTID), em dezembro de 2017, momento que revisitaram seus territórios e detectaram a invasão da mineradora Galvani, é um assunto amplamente discutido nas suas redes de amizade e de solidariedade. Redes sólidas que demonstram que também por parte dos quilombolas há um sistema de comunicação, não tão financeiramente pomposo como o sistema das mineradoras, mas fortemente enraizado no tecido social da região e do país. 
Essa rede social envolve congadeiros, religiosas de matriz africana, pesquisadores, antropólogos, historiadores, procuradores e juristas. Na busca de maior visibilidade, a ARQTOV organiza seminários, seus membros dão entrevistas, deslocam-se constantemente entre pequenas cidades mineiras e grandes centros, como Belo Horizonte, Brasília e Rio de Janeiro.

A rede da ARQTOV se amplia nos apoios que ela recebe da Comissão da Promoção da Igualdade Racial da OAB/MG, nos atendimentos que faz aos diretores e professores de escolas públicas dos municípios do Alto Paranaíba, em seus anseios de compreender melhor a Lei $10.639 / 03^{\text {iv }}$. Alarga-se nas palavras ditas sobre suas experiências sociais aos pesquisadores de várias áreas do conhecimento que pouco a pouco chegam à porta da ARQTOV para buscar informações e dados sobre as comunidades quilombolas da região.

Em rede, a ARQTOV se sente mais protegida e confiante.

Em uma demonstração de sua atuação no combate às desordens provocadas pelos grandes empreendimentos em que, na região do Alto Paranaíba, tomou a frente na defesa da sustentabilidade da região. O fato aconteceu no dia 3/9/2018, no município de Cruzeiro da Fortaleza, data da realização de uma audiência pública na Câmara Municipal para debater questões das atividades da mineradora Galvani, instalada no município de Serra do Salitre, cujos impactos negativos também podem afetar a população de Cruzeiro da Fortaleza.

A audiência foi coberta pela imprensa local e pelos jornais on-line "Agora" e "A Voz do Povo", de Serra do Salitre.

Em resumo, as reportagens descrevem a preocupação da população em manter suas atividades normais, como a preservação da agricultura nas suas diversas modalidades, da qualidade das águas de nascentes que abastecem a população urbana e rural etc.

A audiência contou com a presença do prefeito municipal, Agnaldo Silva, de vereadores, de representantes da mineradora Galvani/Yara, de ONGs, da Federação Nacional das Associações Quilombolas, do Conselho Municipal de Promoção da Igualdade Racial e de membros da população do município.

Em entrevista ao jornal "A Voz do Povo", o presidente da Associação Nacional das Associações Quilombolas, José Ventura, destacou, entre outras questões, que

as próprias mineradoras com seu grupo elas declararam o que era viável ou não para situação da audiência pública da consulta prévia" e ainda ele diz "os povos devem ser consultados, elas não podem falar em nosso nome . Estamos aqui para lutar pelo nosso direito ao território que foi esbulhado. Estamos na busca de direito à nossa preservação, do nosso território, dos nossos costumes (DIVINO, 2018). 
No depoimento do Sr. José Antônio Ventura, percebe-se um processo de tomada de consciência quilombola que se fortaleceu com os movimentos negros, com a promulgação da Constituição de 1988 e sobretudo com a luta contínua.

\section{Considerações finais}

Esse artigo buscou analisar os pilares culturais e as estratégias que fortalecem vínculos sociais comunitários e dotam de poder de argumentação e negociação a Associação dos Remanescentes dos Quilombos das Famílias Teodoro de Oliveira e Ventura (ARQTOV), frente a uma disputa com empresas transnacionais situadas em territórios tradicionalmente ocupados por essas famílias.

Nesse sentido procurou demonstrar que a força da ARQTOV está assente num conjunto de lutas sociais que remontam ao período pós promulgação da Constituição de 1988, momento de redefinição do conceito de quilombo e de ampliação das possibilidades de titulação de terras quilombolas, mas sobretudo, suas estratégias estão ancoradas na contemporaneidade. No embate com o capital minerador transnacional, a ARQTOV fortaleceu suas redes sociais, solidificando de sua parte, canais de comunicação, por meio dos quais veicula suas posições frente ao processo de invisibilização de sua memória, de suas práticas culturais e de devastação e invasão de seus territórios, por parte das mineradoras.

Numa perspectiva antropológica, as comunicações entre empresas transnacionais e comunidades caracterizam-se pelo confronto entre formas de conhecimento e práticas espaciais distintas que operam sobre um mesmo território. São confrontos políticos e simbólicos que, na maioria das vezes, sobrepõem-se à visão capitalista em detrimento das culturas locais. Isso se complica quando pensamos na situação dos quilombos do estado de Minas Gerais, que até momento da escrita desse artigo, fevereiro de 2020, esse estado não possui quilombos titulados pelo INCRA.

No entanto, demonstramos que a ARQTOV, segue atenta, fortalecendo seus vínculos sociais em nível local, mas também nacional.

Nas palavras retiradas de um depoimento do Sr. Ventura ao historiador Jeremias Brasileiro é evidente essa atenção: 
Nós agora temos condições de contar a nossa história sem deixar que tirem o brilho da luta de nossos ancestrais de guerreiros quilombolas, de gente capaz, quiseram nos tirar da história do Brasil, mas somos os quilombos da beira do Rio Paranaíba. (BRASILEIRO, 2017 p.66).

Com essas palavras finalizamos esse artigo.

\section{Referências}

BARTH, Fredrik. Introduction. In: F.Barth (ed.), Ethnic Groups and Boundaries: The social organization of culture difference. Bergen/London, Universitets Forlaget/George Allen \& Unwin, p.9-38. 1969

BRASIL. Constituição (1988). Constituição da República Federativa do Brasil. Brasília, DF: Senado Federal: Centro Gráfico, 1988. 292 p.

BRASIL(2003), Presidência da República. Decreto 4887/03. Disponível em: $\langle$ https://presrepublica.jusbrasil.com.br/legislacao/98186/decreto-4887-03> Acesso em $10 / 09 / 2018$

BORRAS, Saturnino Jr.; FRANCO, Jennifer; PLOEG, Jan D. van der. Introduction: land concentration, land grabbing and people's struggle in Europe. In: FRANCO, Jennifer e

BORRAS, Saturnino Jr. (Eds.). Land concentration, land grabbing and people's struggle in Europe. Amsterdam, Transnational Institute (TNI) e Via Campesina, junho de 2013, p. 6-30.

BRASILEIRO, Jeremias. Rei Ambrósio de Minas Gerais e o ofuscamento da história e da memória de um líder quilombola. Temporalidades - Revista de História, Edição 25, V. 9 , N. 3 (set./dez. 2017)

CARNEIRO DA CUNHA, Manuela. Etnicidade : da cultura, residual mas irredutível, Revista de Cultura e Politica (São Paulo, CEDEC), I (1), 1979

CASTILHO, Araripe . Terras-raras fazem Araxá ser cobiçada pelas mineradoras. Folha de São Paulo, São Paulo, 19 ago 2012. Mercado.

Cedefes (2017) Centro de Documentação Eloy Ferreira da Silva. Comunidade quilombola mineira de Serra do Salitre tem território delimitado. Disponível em < https://www.cedefes.org.br/comunidade-quilombola-mineira-de-serra-do-salitre-temterritorio-delimitado/.> Acesso em 25/01/2020.

DESHAIES, Michel. Grands projets d exploitation minière et stratégie des firmes pour se rendre environnementalement acceptables. Revista L'Espace Politique. Vol. 15 n.3, 2011.

DIVINO, Fabiano. Serra do Salitre, MG: Quilombolas, estiveram na Procuradoria da Republica para denunciar os vários bens que estão na área quilombola que estão sendo 
destruídos. Disponível em: < http://avozdopovo.org/serra-do-salitre-mg-quilombolasestiveram-na-procuradoria-da-republica-para-denunciar-os-varios-bens-que-estao-na-areaquilombola-que-estao-send/ > . Acesso em: 10/02/2020

Cruzeiro da Fortaleza: Administração municipal, legislativo,

Ong `s, COMPIR, Federação dos Associações Quilombolas- FENAQ e população realizam, audiência publica para debater sobre a mineradora de Serra do Salitre, sobre os possíveis impactos. Disponível em < http://avozdopovo.org/cruzeiro-da-fortalezaadministacao-municipal-legislativo-ongs-compir-federacao-nacional-das-associacoesquilombolas-fenaq-e-populacao-reali/ > Acesso em 10/02/2020

EDELMAN, Marc e LEÓN, Andrés. Cycles of land grabbing in Central America: an argument for history and a case study in the Bajo Aguán, Honduras. Third World Quarterly. Vol. 34, nº. 9, 2013, p. 1697-1722 (Número especial sobre Global Land Grabs).

G1 PORTAL DE NOTICIAS. Mineradora em Serra do Salitre prevê geração de mais de 2 mil empregos. Disponível em: < G1.globo.com/minas-gerais/triangulomineiro/concursos-e-emprego/noticia/2016/11/mineradora-em-serra-do-salitre-prevegeracao-de-mais-de-2-mil-empregos.html>. Acesso em: 1 de dezembro 2019.

LUCCHESI, C. e CUADROS, A. "Nióbio faz dos Moreira Salles a família mais rica do Brasil" 13/03/2013. Disponível em <http://exame.abril.com.br/negocios/niobio-faz-dosmoreira-salles-a-familia-mais-rica-do-brasil// > Acesso em 15/02/2020.

MARQUES, Carlos. 2009. De Quilombos a Quilombolas: Notas Sobre Um Processo Histórico-Etnográfico. Revista De Antropologia 52 (1), 340-74. São Paulo: USP, 2009.

O'DWYER, Eliane Cantarino (org.). Quilombos. Identidade étnica e territorialidade. Rio de Janeiro: Editora FGV, 2002.

OLIVEIRA,Elida. Brasil investe para vender nióbio à China. Folha de São Paulo, São Paulo, 10 nov 2011, Mercado.

SAUER, Sérgio e BORRAS, Saturnino. Land grabbing e Green grabbing: uma leitura acadêmica, sobre a apropriação global de terras. Revista Campo - Território. Vol 11, n.23, 2016.

SAUER,S. e LEITE, Sergio. Expansão Agricola, preços e apropriação de terras por estrangeiros no Brasil. Revista de Economia e Sociologia Rural. Vol 50, n.3, 2012.

SCHMITT, Alessandra; TURATTI, Maria Cecília Manzoli; CARVALHO, Maria Celina Pereira de. A atualização do conceito de quilombo: identidade e território nas definições teóricas. Ambient. soc., Campinas, n. 10, p. 129-136, Junho 2002 .Disponível em $<$ http://www.scielo.br/scielo.php?script=sci_arttext\&pid=S1414753X2002000100008\&lng=en\&nrm=iso >.Acesso em 14/01/2020

SILVA, Jóse C. Congado e cultura centro-africana: marcas da ancestralidade. In: CLEMENTE,C.C e SILVA, J.C.(Org.) Negros, cultura e vida urbana: estudos etnográficos sobre o Congado. Uberlandia: RBdigital, 2013. 
WEBER, Max. Economia e sociedade, vol. 1, São Paulo, Imprensa Oficial/Ed. UnB, 2004.

WOLFFENBÜTTEL, Andréa. Investimento Estrangeiro Direto. Revista Desafios do Desenvolvimento- IPEA, 2006. Disponível em: < http://desafios.ipea.gov.br/index.php?option=com_content\&view=article\&id=2103:catid=

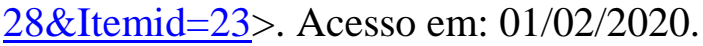

ZHOURI, Andréa et al. O desastre da Samarco e a política das afetações: classificações e ações que produzem o sofrimento social. Cienc. Cult., São Paulo, v. 68, n. 3,Set.2016.

Disponível em <http://cienciaecultura.bvs.br/scielo.php?pid=S0009-

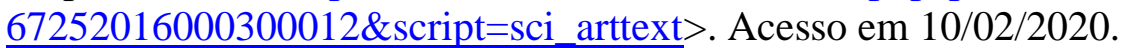

Submetido em: 19/02/2020

Aprovado em: 22/06/2020

Publicado: $23 / 09 / 2020$

\begin{abstract}
' É professora de Antropologia na Universidade Federal de Uberlândia em Minas Gerais, realizou pósdoutoramento com bolsa Estágio Senior CAPES na École Hautes Études en Sciences Sociales (2015/2016) possui doutorado em Ciências Sociais com concentração em Antropologia pela Pontifícia Universidade Católica de São Paulo (2005) com formação complementar na École de Hautes Études en Science Sociales (EHESS/PARIS)Email claudelircc@gmail.com
\end{abstract}

ii Centro de Documentação Eloy Ferreira da Silva

iii Redescoberta, porque a existência de terras raras com presença de nióbio já era algo de conhecimento do setor empresarial mineral desde os anos de 1960, quando a mineradora Molycorp vendeu sua mina em Araxá ao banqueiro brasileiro Walther Moreira Salles. De acordo com a revista Exame, na época não havia mercado para o uso comercial do metal. Assim, ele seria redescoberto em suas propriedades de uso tecnológico apenas na primeira década do século XXI. Ver revista Exame disponível em < https://exame.abril.com.br/negocios/niobio-faz-dos-moreira-salles-a-familia-mais-rica-do-brasil/> . Acesso em: 10/12/2019.

iv Em 2003 foi sancionada a Lei 10639/03 que alterou a Lei de Diretrizes e Bases da Educação que inclui no currículo oficial da Rede de Ensino a obrigatoriedade da presença da temática "História e Cultura AfroBrasileira e Africana". 